
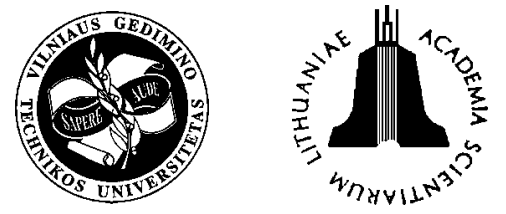

ISSN $1392-3730$

JOURNAL OF CIVIL ENGINEERING AND MANAGEMENT

http:/www.jcem.vgtu.lt

2004, Vol X, No 4, 255-260

\title{
EXPERIMENTAL STUDY OF TRANSIENT THERMAL CREEP AND OTHER PHENOMENA OF CONCRETE AT HIGH TEMPERATURE
}

\author{
Horacio Colina, Gilles Moreau, Daniel Cintra \\ Laboratory of Material Analysis and Identification (LAMI), Institut Navier, ENPC-LCPC, \\ 6 et 8 ave Blaise Pascal-Cité Descartes, Champs sur Marne - 77455 Marne-la-Vallée Cedex 2, France. \\ E-mail: colina@lami.enpc.fr
}

Received 23 Sept 2004; accepted 10 Nov 2004

\begin{abstract}
This paper deals with experimental study of transient thermal creep and other parameters, as elastic and free thermal strain, of ordinary, high-strength and high-performance concrete at high temperature. An original test device can reproduce accident and service conditions with a homogeneous distribution of temperature inside the specimens. Constant values of heating rate and force (when the specimen is loaded) are applied. Successive constant temperature levels are reached and maintained during the necessary time to ensure internal stabilisation. To observe the importance of changes in concrete properties after a first heating cycle, some specimens are submitted to a second one. In order to show the performance of the experimental methods, some results are presented and discussed.
\end{abstract}

Keywords: concrete at high temperature, experimental method, accident condition, service condition, transient thermal creep, elastic strain, free thermal strain.

\section{Introduction}

High temperatures have a significant effect on concrete even for moderate heating rates. The internal structure of concrete changes and defects develop, owing to free and bound water loss, decarbonation and other physical and chemical phenomena. Macroscopically, damages are principally materialised by irreversible strains and variations of strength and elastic modulus [1-3].

The principal objective of this work is the experimental study of a particular form of thermal strain: the usually called transient thermal creep $[2,4,5]$. Above some values of temperature, strains are far different from those of the only effect of elastic strains, drying shrinkage and basic creep could be [6,7]. Therefore, another strain component must to be considered for explaining clearly the concete behaviour at high temperatures.

For temperatures near to $100{ }^{\circ} \mathrm{C}$, transient thermal creep seems to adapt the thermal incompatibilities between the cement paste which shrinks and the gravel which expands [8]. For higher temperatures, changes caused by dehydration of the cement paste also take part in the phenomenon. The important magnitude of transient thermal creep helps avoiding excessive damage during heating. This effect is, however, restricted to the heating phase and does not appear during cooling, leading to irrecoverable strains $[8,9]$.

An accurate test device was mounted to follow the transient thermal creep evolution $[10,11]$. It has also permitted to study the free thermal strain and the evolution of the elastic strain with temperature. The determining factor of the test design has been used to obtain a quasi-uniform distribution of temperature inside the material in order to avoid gradient effects.

Hereafter, tests for following the thermal strains on ordinary, high-strength and high-performance concrete are described.

\section{Materials and test methods}

The RILEM recommendations TC 129-MHT concerning transient creep under service conditions [2] have been followed as a general framework for the design of the tests. One of the main recommendations concerns temperature gradients within the specimen thickness which are to be as limited as possible during the test.

In order to calculate the real transient thermal creep, the instantaneous elastic strain has been measured during the tests. Other authors $[1,8,12,13]$ deduce only the initial elastic strain to determine the transient thermal creep strains, called in this case "load-induced thermal strains" (LITS).

\subsection{Heating conditions}

Two heating conditions have been considered in the experimental programme:

- Accident conditions, involving short-term exposure 
of drying concrete to high temperatures. According to Rilem recommendations [6] for the tested specimens $(160 \mathrm{~mm}$ diameter), this condition can take place from a constant heating rate of $0,5^{\circ} \mathrm{C} / \mathrm{min}$.

- Service conditions, considering long-term exposure of drying or moisture saturated concrete to high temperatures. According to Rilem recommendations [6] for the tested specimens (160 mm diameter), this condition happens at a constant heating rate of about $0,1^{\circ} \mathrm{C} / \mathrm{min}$.

In practice, accident conditions correspond with temperatures that can reach $700{ }^{\circ} \mathrm{C}$ or more, while service conditions rarely go beyond $200{ }^{\circ} \mathrm{C}$.

In this paper, tests reproducing both conditions with drying concrete are described, although the principal results correspond to service conditions because it was the principal objective of the initial experimental programme [11]. Experiments reproducing accident conditions in high performance concrete are included in the experimental part of a $\mathrm{PhD}$ thesis, which results will be available in 2005 [14].

\subsection{Materials and specimens}

In order to obtain a uniform distribution of temperature within the specimens, hollow cylinders were cast to heat the specimens from the inside part, the external surface, the top and the bottom of the cylinder. A length/ diameter ratio of 4 has been chosen to permit an accurate measurement of strains in the central part of the specimen. The specimen dimensions were $160 \mathrm{~mm}$ for the external diameter, $30 \mathrm{~mm}$ for the internal one and $640 \mathrm{~mm}$ for the length.

Fig 1 shows the specimen, scheme with details of the heating device, the metrology system and the test setting.

Three different kinds of concrete were tested: an ordinary concrete, a high strength concrete and a high performance concrete, with $35 \mathrm{MPa}, 60 \mathrm{MPa}$ and 100 $\mathrm{MPa}$ as compressive strength respectively (for more information about concrete mix see [15]).

A single batch of concrete for three $160 \times 640 \mathrm{~mm}$ hollow specimens and four $160 \times 320 \mathrm{~mm}$ cylinders for resistance controls was made at each opportunity. It was poured in the respective moulds and each layer used for filling up the moulds was vibrated with a vibrating needle.

Immediately after casting, the moulds were hermetically closed and the specimens moist cured during 72 hours. After being removed from moulds, they were stored under water at $20 \pm 2{ }^{\circ} \mathrm{C}$, at least during 70 days, until the moment of the test.

\subsection{Test device}

The choice of hollow cylinders has permitted to reduce the thickness of the heated zone: $65 \mathrm{~mm}$ in the radius direction instead of $160 \mathrm{~mm}$ for the full cylinder.

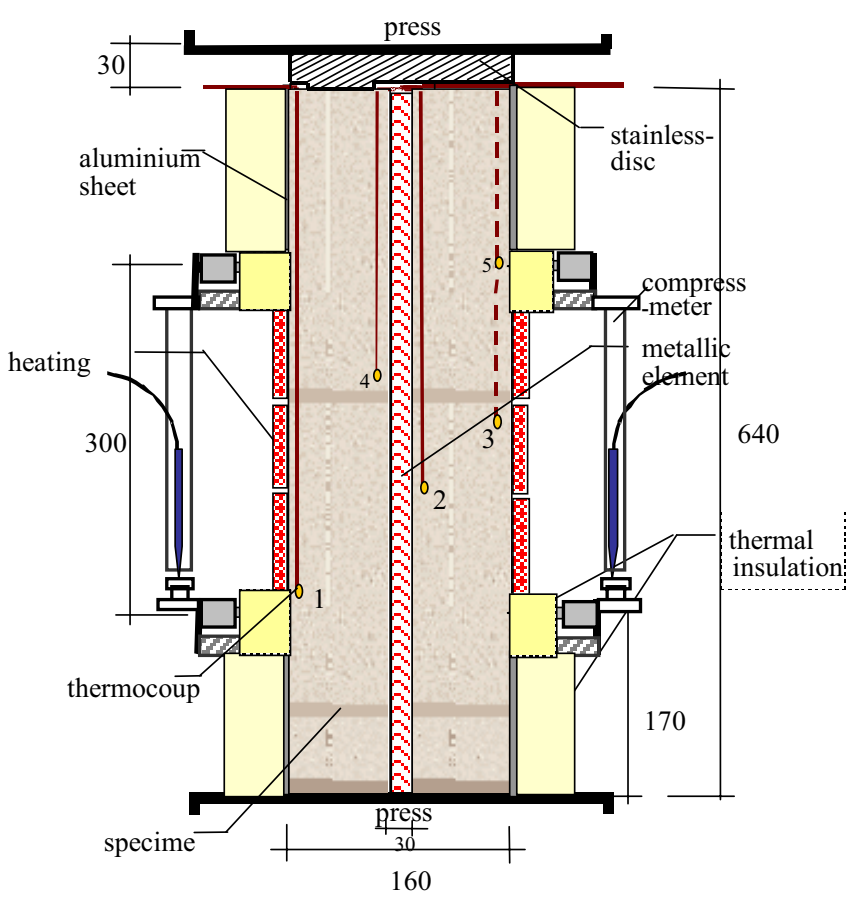

Fig 1. Scheme of the transitional thermal creep test device (measures in $\mathrm{mm}$ )

Heating was provided by heating collars, heating plates of the power press, and a metallic element of high thermal conductivity. This heating device ensured a uniform temperature within the specimen during the tests.

The specimens were then heated from the external surface in the central part by three heating collars, through the two plates of the heating power press, specially adapted for the test, and from the inside part by the way of a heat-conductor metallic element. On the upper part, a particular stainless-steel disk has let thermocouple cables come out and has allowed the transmission of heat and pressure from the press plate. In order to keep the temperature of the lower and the upper part of the specimen near that of the central part, the external surface was covered with aluminium sheets and recovered with a $50 \mathrm{~mm}$ layer of thermal insulation.

To measure length variations in the direction of the central axis of the specimen, a distance of $300 \mathrm{~mm}$ between two cross-sections situated at $170 \mathrm{~mm}$ of the top and the bottom respectively, was considered as basic length. Length variations during the test were then measured by a compressometer rig specially conceived for this experiment: two rings were clamped to the specimen at the level of each reference cross-section by three screws equally spaced around the circumference and connected to the rings by means of elastic strips. The displacements were measured employing three linear variable transducers (LVDT) located into invar supports mounted vertically at $120^{\circ} \mathrm{C}$ intervals around the specimen. In case of exceeding the temperature limit of LVDTs, $70{ }^{\circ} \mathrm{C}$, a water cooling system was provided in the upper part of the invar tubes. 
For measuring the internal temperatures, five thermocouples of $\mathrm{K}$ type, with $700{ }^{\circ} \mathrm{C}$ as maximum temperature tolerance, were placed inside the specimen (Fig 1): three at $10 \mathrm{~mm}$ from the external surface (numbers 1,3 and 5) and two at $10 \mathrm{~mm}$ from the internal surface (2 and 4). Thermocouples 1 and 5 were situated at the level of the reference cross-section, number 3 at the middle and numbers 2 and 4 at $100 \mathrm{~mm}$ from their respective cross-section.

The test machine was a heating press with $900 \mathrm{kN}$ as closing power, $4000 \mathrm{~W}$ as heating power in each plate and $700 \mathrm{~mm}$ of separation between the plates when stopped. In Fig 2 we can see the test machine with the specimen and the equipment employed for the data acquisition during the experiment.

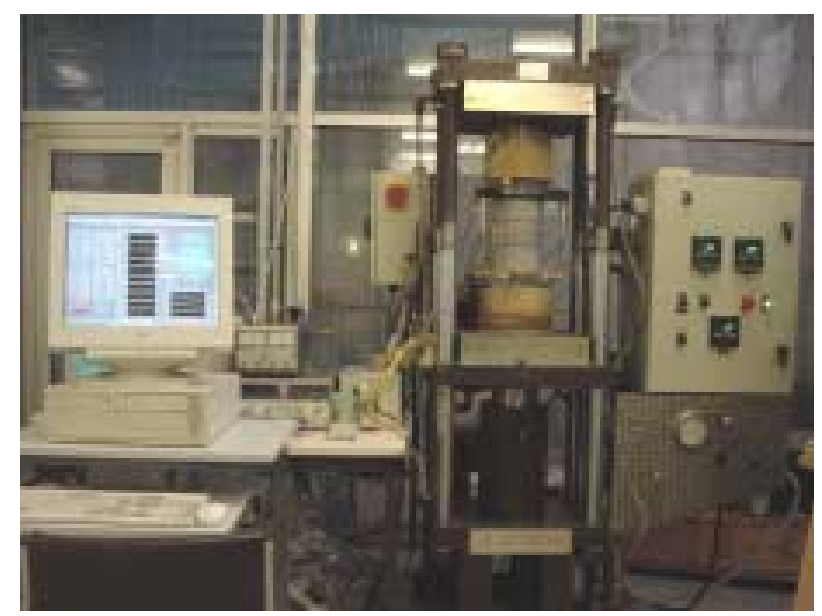

Fig 2. General view of the test device for transient thermal test of concrete

The test data were acquired by a National Instruments ${ }^{\circledR}$ data acquisition system connected to a PC computer, where the Labview ${ }^{\circledR}$ software permitted to observe in real time the evolution of temperature and strain during the experiment, and to store the numerical output for data processing.

\subsection{Test development}

Before testing, the specimens were dried at $60{ }^{\circ} \mathrm{C}$ during $48 \mathrm{~h}$, and the weight loss depended on the concrete type: $1,5 \%$ for ordinary concrete, $1,0 \%$ for highstrength concrete and $0,6 \%$ for high-performance concrete, in average values. After that they were conveniently prepared: the lower surface of the specimen was rectified, and the aluminium sheets, the compressometer rig and the insulation layers were mounted.

Finally, the thermocouples were put inside their correspondent cavities, the upper surface was covered with a thin layer of mortar, the stainless-steel disk was put on and the whole was set into the heating press. During a short time, a pre-compression of $1 \mathrm{MPa}$ was applied in order to assure centring the specimen.
After verification of the well positioning of the specimen, a uniaxial compressive load was applied at a rate of $1 \mathrm{MPa} / \mathrm{s}$ until the selected constant load was reached. In these experiments the $20 \%$ reference "cold" $\left(20^{\circ} \mathrm{C}\right)$ strength value was chosen as the constant load.

Immediately, the specimen was heated at a constant rate of $0,1{ }^{\circ} \mathrm{C} / \mathrm{min}$ for service conditions or $0,5^{\circ} \mathrm{C} / \mathrm{min}$ for accident conditions, until the first level of constant temperature was reached. The stage was maintained till stabilisation of internal temperature, during a time which depends fundamentally on tests conditions (accident or service conditions) and constant temperature level (Figs 3-6). Then the constant heating rate was restarted in order to reach the next temperature stage.

When the heating part was completed, the warm device was turned off to follow the "natural" cooling part of the cycle. At the test end, when ambient temperature was reached inside the material, the specimen was unloaded.

The first temperature stage was always chosen at a temperature level higher than $105^{\circ} \mathrm{C}$ in order to study the phenomenon after free water evaporation and the beginning of dehydration of C-S-H [2, 4, 8, 9].

To study whether the phenomenon can develop again after a cycle of heating-cooling at constant load, some specimens were submitted to a new cycle with two temperature stages: the first at a temperature level lower than the maximum temperature reached during the $1^{\text {st }}$ cycle and the second one at a higher one (for further information, see [15]).

In every test, the elastic strain was recorded at the beginning of the test when loading, during the temperature stages by means of an unloading-loading quasi-instantaneous process (not more than 2 min of duration), and at the end of the cycle when unloading the specimen already cold.

The free thermal strain, also necessary for the determination of the transient thermal creep $[2,6]$, was obtained by submitting virgin specimens to a cycle of heating-cooling similar to the first cycle of heating-cooling with constant load but without loading the specimen [15].

\section{Results and discussion}

The results presented in this part include the evolution of temperature and total strain during two heatingcooling cycles at constant load, and during free thermal strain tests. From these data, the transient thermal creep may be calculated and compared for the different types of concrete [15].

In paper [15] the results obtained are treated in detail. Hereafter, a general review is given to show the pertinence of the test method.

\subsection{General results}

The general evolutions of two mean temperatures and the total strain for both test conditions are given here. 
$\mathrm{T}_{\mathrm{a}}$ represents the temperature evolution near the central axis and $\mathrm{T}_{\text {ref }}$ in the central zone of the specimen. The $\left|T_{a}-T_{\text {ref }}\right|$ difference gives a measure of the uniformity of temperature inside the material. It has not exceeded $6{ }^{\circ} \mathrm{C}$ in any case [15].

The mean total strain $\mathrm{e}_{\mathrm{tot}}$ is determined as the average of the three deformations obtained from the LVDT measures. The "peaks" in the strain curves correspond to the elastic strains.

Concerning accident conditions, only one test at $0,5^{\circ} \mathrm{C} / \mathrm{min}$ was carried out because the initial research programme [11] was based on service conditions. Nevertheless, it has permitted to verify the performance of the test device for studying this kind of solicitation and it is actually employed in the experimental part of a $\mathrm{Ph}$ $\mathrm{D}$ thesis dealing with this subject [14]. Fig 3 shows the evolution curves for this test, which was performed with an ordinary concrete specimen.

For service conditions, the specimens were heated at a constant rate of $0,1^{\circ} \mathrm{C} / \mathrm{min}$ up to successive temperature levels (of about $140,190,220^{\circ} \mathrm{C}$ ), which were maintained constant during the necessary time to ensure the stabilisation of internal temperatures. Figs 4, 5 and 6 show the general evolutions for ordinary concrete, high strength concrete and high performance concrete respectively.

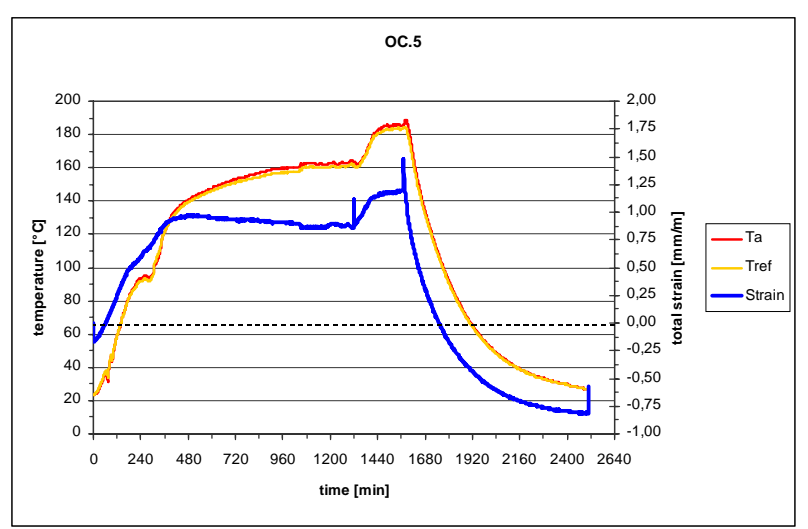

Fig 3. Temperatures and total strain evolution for an ordinary concrete under accident conditions

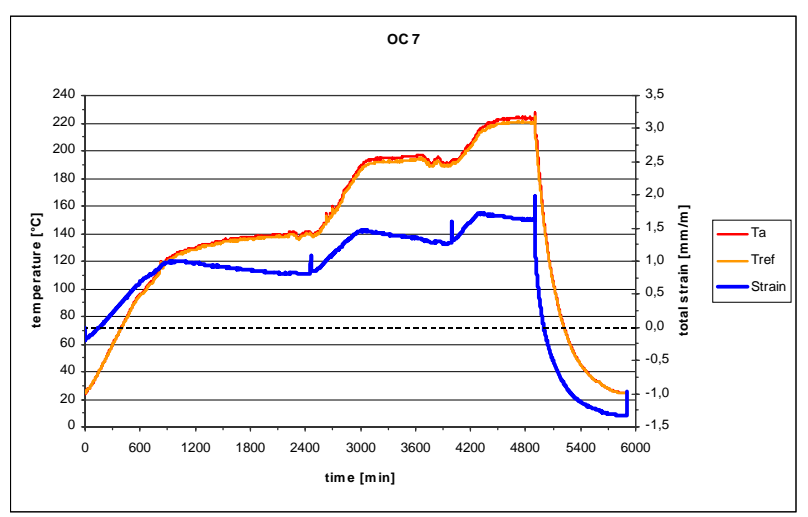

Fig 4. Temperatures and total strain evolution for an ordinary concrete under service conditions

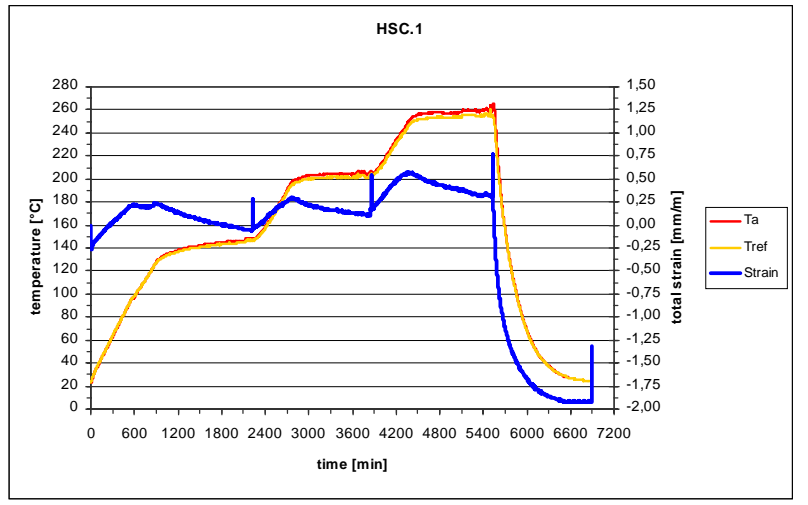

Fig 5. Temperatures and total strain evolution for a high strength concrete under service conditions

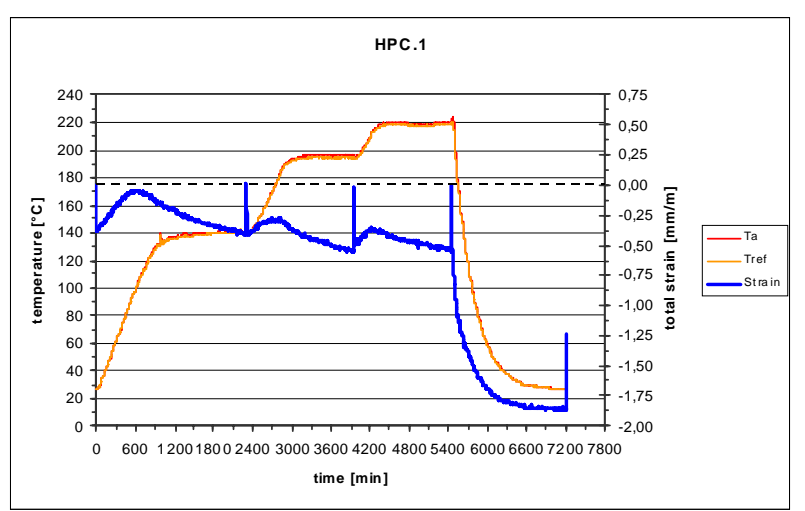

Fig 6. Temperatures and total strain evolution for a high performance concrete under service conditions

After a period of at least a week at ambient conditions, some specimens were submitted to a new cycle of heating-cooling with two temperature stages: the first at a temperature level lower than the maximum already reached during the first cycle and the second at a higher one. In every case, the transient thermal strain has not developed during the first stage but it has appeared again at the second one. Fig 7 shows the correspondent curve for a high strength concrete specimen.

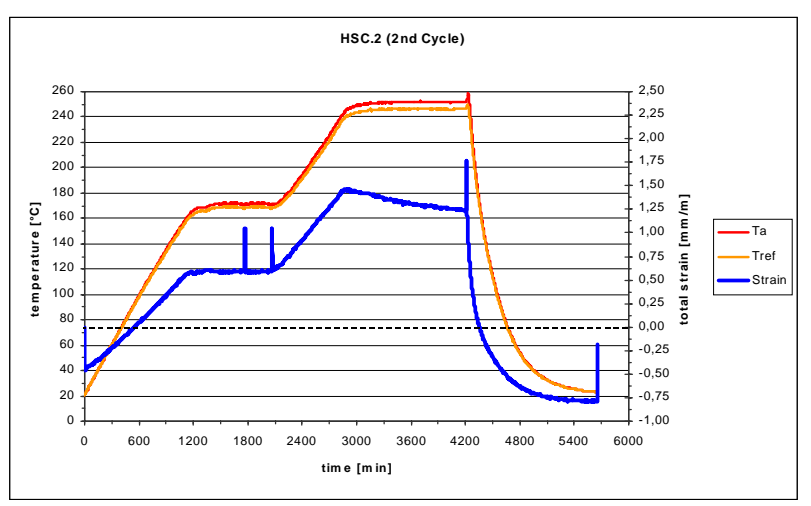

Fig 7. Temperatures and total strain evolution for a high strength concrete, under service conditions, during a new 
cycle of heating-cooling.

It is interesting to note the two equal values of elastic strain during the first temperature stage, which show that this strain depends only on load and temperature [2].

\subsection{Brief analysis and discussion}

The existence of a strain component, which reduces the material expansion when heating is clearly shown by the experimental method, used in this work. It can be seen in the temperature and total strain evolution curves of the first cycles of heating-cooling and those of the second cycles when the maximum temperature of the first one is exceeded. The residual strain at the end of the test shows that it is irrecoverable and that its value is important, varying with the kind of concrete.

Complementary expansion test without load (free thermal strain) plus the elastic strains obtained during the principal test permit to estimate the values of transient thermal creep of concrete [15].

Thus, considering the additive approach valid to describe the strain behaviour $[1,2,6,7,8]$, transient thermal creep $\varepsilon_{t t c}\left(T_{j}, \sigma\right)$ can be estimated, for the temperature $T_{j}$ corresponding to the $j$ stage, by:

$$
\varepsilon_{t t c}\left(T_{j}, \sigma\right)=\varepsilon_{t o t}\left(T_{j}, \sigma\right)-\varepsilon_{e l}\left(T_{j}, \sigma\right)-\varepsilon_{t h}\left(T_{j}, 0\right),
$$

where:

$\varepsilon_{t o t}\left(T_{j}, \sigma\right)$ is the total thermal strain and

$\varepsilon_{t h}\left(T_{j}, 0\right)$ the free thermal strain

corresponding to the time when internal temperatures reached the $T_{j}$ value,

$\varepsilon_{e l}\left(T_{j}, \sigma\right)$ is the elastic strain measured during the $j$ stage.

The principal importance of transient thermal creep phenomenon is its beneficial effect when heating because it reduces the material expansion, but also its contribution to the strain values when cooling which can provoke tensile stress in concrete higher than its strength $[8,9]$.

When comparing the curves for ordinary concrete in accidental and service conditions, it is only possible to say that this concrete shows a higher thermal inertia to reach the internal stabilisation during accident conditions. Only one temperature stage was maintained the necessary time when testing at accidental conditions. The existence of a transient thermal strain can also be observed but it seems to be of lower intensity than under service conditions. More experiments will be made [14] to state further conclusions.

Considering the second cycles of heating-cooling, it has been always found the same behaviour: any strain variation during the first temperature stages and a new development of the phenomenon for the second ones. Thus the transient thermal creep depends only on irrecoverable physical and chemical processes taking place in the material due to the temperature increase [15].
The technique used for obtaining the elastic strains has also permitted to estimate the Young's modulus and to follow its evolution during the process [10]. Its "hot" value can be estimated by the ratio between the constant stress and the "hot" elastic strain, which corresponds to the absolute value of the total strain difference measured during the quasi-instantaneous process of unloading and loading. Fig 8 shows the tendency obtained for the heating part of the $1^{\text {st }}$ cycles of heating-cooling, for three concretes.

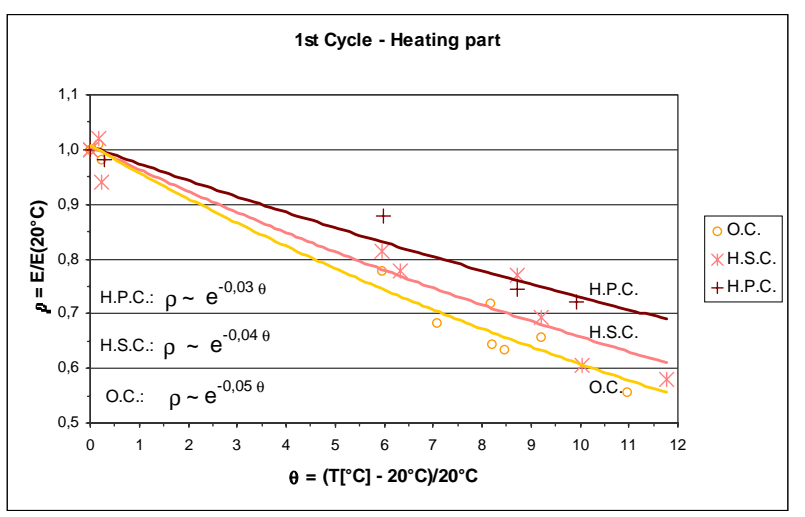

Fig 8. Young's modulus evolution with temperature for three concretes during the heating part of the 1 st cycle

Finally, it is interesting to observe (Figs 3-7) that with this test device the uniformity of temperature inside the central part of the specimen is assured: in any case $\left|\mathrm{T}_{\mathrm{a}}-\mathrm{T}_{\text {ref }}\right|$ has exceeded $6{ }^{\circ} \mathrm{C}[15]$.

\section{Conclusions}

The experimental method presented here permits to observe temperature and strain evolutions of different kinds of concrete during cycles of heating-cooling.

A special shape of the specimens and the heating system ensure a uniform temperature field inside the material, without temperature gradients, which is a principal condition for studying the transient thermal strains.

The data acquisition system permits to follow in real time the evolution of temperatures, displacements and force and to make a detailed analysis of the results.

The obtained results put in evidence the existence of a transient thermal strain, so-called transient thermal creep, which develops during the first heating process and also during a new one if the maximum temperature of the first cycle is exceeded.

The experimental techniques used in this work allows to follow the total strain evolution under constant load and the elastic strain evolution with temperature, owing to the possibility of unloading and loading the specimen in a quasi-instantaneous way during the process. The free thermal strain is obtained with a similar test device without load. 
Thus, for the mean reference temperature of a stage, the transient thermal creep can be easily estimated from eq 1 with the total and free thermal strains values obtained from the strain-temperature curves, plus the "hot" elastic strain value determined during the stage.

This technique also allows to estimate the Young's modulus variation with temperature, for different concretes under the same test conditions, by the ratio between the constant stress and the values of the elastic strain at the beginning of the test, for each temperature stage and at the end of the experiment.

The test by temperature stages is a relevant way for studying the thermal behaviour of concrete. In future works a more complete description of the phenomena, concerning accidental conditions, may be obtained by including more temperature stages and an accurate study of the length of each stage.

\section{References}

1. Khoury, G. A.; Grainger, B. N. and Sullivan, P. J. E. Transient thermal strain of concrete: Literature review, conditions within specimen and behaviour of individual constituents. Magazine of Concrete Research, 37 (132), 1985, p. 131-144.

2. Schneider, U. Concrete at high temperatures - A general review. Fire Safety Journal, 13, 1988, p. 55-68.

3. Guo, J. S. and Waldron, P. Development of the stiffness damage test (SDT) for characterisation of thermally loaded concrete. Materials and Structures, 33, 2000, p. 483-491.

4. RILEM TC 129-MHT. Test methods for mechanical properties of concrete at high temperatures. Recommendations: Part 7: Transient creep for service and accident conditions. Materials and Structures, 31, 1998, p. 290-295.

5. Küttner, C. H. and Ehlert, G. Experimental investigations of transitional creep of concrete at temperatures up to $130{ }^{\circ} \mathrm{C}$ and boundary moisture conditions. Wiss. Hochsch. Archit. Bauwes-B-Weimar, 38, 1992, p. 211-218.

6. Khoury, G. A.; Grainger, B. N. and Sullivan, P. J. E. Strain of concrete during first heating to $600{ }^{\circ} \mathrm{C}$ under load.
Magazine of Concrete Research, 37 (133), 1985, p. 195215 .

7. Cheyrezy, M. Fire behaviour of high performance concrete. Continuing education course on fire security and concrete structures, Ecole Nationale des Ponts et Chaussées, Paris, 2000. 28 p. (in French).

8. Khoury, G. A. Compressive strength of 1992, p. 291-309.

9. Feraille-Fresnet, A. The water role in concrete behaviour at high temperature (Le rōle de l'eau dans le comportement ą haute température des bétons). Ph D thesis, Ecole Nationale des Ponts et Chaussées, Paris, France, 2000 (in French).

10. Colina, H. and Moreau, G. Transient thermal creep of concrete: An interesting test method. In: Proceedings of the 8th international conference "Modern Building Materials, Structures and Techniques", Vilnius, 19-22 May 2004. Selected papers, ed E. K. Zavadskas, P. Vainiūnas and F. M. Mazzolani. Vilnius: Technika, 2004, p. 379-383.

11. Colina, H. Study of transient thermal creep of concrete (Etude du fluage thermique transitoire du béton). Advancement report of CEA-ENPC research project, 2000. 27 p. (in French).

12. Thienel, K.-Ch. and Rostasy, F. S. Transient creep of concrete under biaxial stress and high temperature. Cement and Concrete Research, 26 (9), 1996, p. 1409-1422.

13. Pimienta, P. and Hager, I. Evolution of HPC characteristics submitted to high temperatures. Report of HPC 2000 National Project, France, 2000. 28 p. (in French).

14. Sabeur, H. Study of concrete behaviour under accidental conditions and high temperatures - A thermal-hydro-chemical-mechanical coupled approach (Etude du comportement $\mathrm{du}$ béton en conditions accidentelles sous hautes températures - Une approche Thermo-Hydro-ChimicoMécanique couplée). $1^{\text {st }}$-year advancement report of $\mathrm{PhD}$ thesis, Ecole Nationale des Ponts et Chaussées, Paris, France, 2004 (in French).

15. Colina, H. and Sercombe, J. Transient thermal Creep of concrete at temperatures up to $300{ }^{\circ} \mathrm{C}$ under service conditions. Accepted by Magazine of Concrete Research, 56, 2004. 